\title{
Original Preticle
}

\section{Investigation of the effects of certain formulation factors on release properties of paracetamol tablets using $2^{3}$ factorial design. Amani Elsayed ${ }^{1}$, Ahmed-Al-Badawi $^{2}$, Asim Sir Al-Khatim $^{2}$, Khalid Mohammed $^{2}$}

\begin{abstract}
Objective: To study the effects of three formulation variables (PVP, stearic acid and Avicel PH101) on disintegration time and release properties of paracetamol tablets using a $2^{3}$ factorial experimental design.

Methodology: Three formulation variables; Polyvinyl pyrrolidone (factor A), Stearic acid (factor B) and Avicel PH 101 (factor C) were used at two concentrations levels in paracetamol tablet formulation. The estimated effects of increasing the factors from a low to a high level were tested for significance by analysis of variance. The release properties of the tablets- measured by the disintegration and the dissolution times were used as assessment parameters.

Results: Changing the concentration of factor A from" low" to "high" led to an increase in the disintegration time of the tablets. The disintegration of the tablets is not affected by factor B or C. All investigated factors in $2^{3}$ factorial design had a significant effect on dissolution time. The ranking of the factors was $\mathrm{C}>\mathrm{B}>\mathrm{A}$.

Conclusion: The results suggest that factorial design could be useful to produce tablets with particular drug release profiles and there was a considerable interaction between the variables employed on the tablet dissolution rate.
\end{abstract}

Key Words: Pyrrolidone, Stearic acid, Avicel.

U ntil recently, pharmaceutical
formulation and processes were
investigated and developed simply by trial and error while varying one factor at a time. This approach is both time and energy consuming and is as well costly. Furthermore, misleading conclusions can be drawn, particularly when different variables interact ${ }^{1}$. Factorially designed experiments are intended to avoid such problems. It is a system of experimental design by which factors involved in a reaction or a process can be identified and their relative importance assessed. It is thus a means of separating those factors, which are important from those, which are not $^{2,3}$. Sanderson et al. studied various formulation and process factors and evaluated interaction between those factors using $2 \times 2 \times 2 \times 3$ factorial design. The factors studied are mixing time, starch concentration,

1. Assistant Prof., Faculty of Pharmacy, University of Gezira, Wad Medani, Sudan.

2. Dr. Amipharma Laborotaries, Sudan. Correspondencer: email: amanina100@yahoo.com Mobile: 00249912411250 drug particle size and compaction pressure ${ }^{4}$. In another study Mahmude et al. assessed the effects of glycine, taurine and sorbitol on the intrinsic dissolution rate of aspirin using $2^{3}$ factorial design 5 .

Paracetamol is an important drug used in mild to moderate pain, and to control fever ${ }^{6}$.The release properties must fit the need for it is use; for example fast release is needed to relieve acute pain while long acting paracetamol is needed for chronic pain. Based on novel drug delivery system, two dosage of paracetamol in a day are sufficient for patients to control fever and pain instead of taking 3-4 tablets of conventional oral paracetamol pills.

In the present study, eight experiments were conducted in one block using $2^{3}$ factorial design. The levels of excipients were changed in order to have both fast and long acting paracetamol preparations. 


\section{Materials and Methods \\ Materials}

Paracetamol powder, Avicel pH 101, Povidone (PVP), and stearic acid were kindly donated by Amipharma Laborotaries (Sudan). Single lots of each excipient were used throughout this work.

\section{Methods}

\section{Preparation of paracetamol tablets}

(Each batch contain 700 tablets) in all experiments $357 \mathrm{gms}$ of paracetamol was weighed and added to a part of Avicel pH 101 and mixed for 10 minutes. Then it was moistened with PVP to produce a wet mass which, was passed through a mesh of size 16 manually to produce granules. The granules were spread in trayers and dried in an oven at $90{ }^{\circ} \mathrm{C}$ for $5 \mathrm{~min}$. The dried granules were sized by a mesh of size 20 . The other half of Avicel $\mathrm{pH} 101$ was added. Stearic acid was then added and mixed for 5 min. Finally it was compressed into tablets using the rotary press tableting machine with a flat punch (Samco Machinery Limited, Canada).

\section{Factorial Design}

To screen for the most important factors that affect the disintegration and dissolution of paracetamol tablets an experimental design was set up. The effects of three formulation variables (PVP, stearic acid and Avicel PH101) on disintegration time and the time for $80 \%(\mathrm{t} 80 \%)$ of the drug to be released were studied in a conventional $2^{3}$ factorial design. All processing variables were kept constant. The levels of the investigated factors are depicted in Table 1 and the experiments were set up as shown in Table 2.

Table 1: level of the three factors of the factorial design

\begin{tabular}{|c|c|c|}
\hline Factor & $\begin{array}{l}\text { low level } \\
(\mathrm{mg})\end{array}$ & $\begin{array}{l}\text { High level } \\
(\mathrm{mg})\end{array}$ \\
\hline A: Binder (PVP) & 10 & 20 \\
\hline $\begin{array}{l}\text { B: Lubricant } \\
\text { (stearic acid) }\end{array}$ & 5 & 10 \\
\hline $\begin{array}{l}\text { C: Diluent } \\
\text { (Avicel PH 101) }\end{array}$ & 70 & 85 \\
\hline
\end{tabular}

Table2. The matrix of the factorial design

\begin{tabular}{c|ccc}
$\begin{array}{c}\text { Experiment } \\
\text { No. }\end{array}$ & $\begin{array}{c}\text { PVP } \\
(\mathrm{mg})\end{array}$ & $\begin{array}{c}\text { Stearic } \\
\text { acid(mg) }\end{array}$ & $\begin{array}{c}\text { Avicel } \\
(\mathrm{mg})\end{array}$ \\
\hline 1 & 10 & 5 & 70 \\
$\mathrm{a}$ & 20 & 5 & 70 \\
$\mathrm{~b}$ & 10 & 10 & 70 \\
$\mathrm{ab}$ & 20 & 10 & 70 \\
$\mathrm{c}$ & 10 & 5 & 85 \\
$\mathrm{ac}$ & 20 & 5 & 85 \\
$\mathrm{bc}$ & 10 & 10 & 85 \\
$\mathrm{abc}$ & 20 & 10 & 85
\end{tabular}

All experiments were performed in duplicate to allow estimation of the experimental error (replicate I and II). The experiments were performed in randomized order as follows c, bc, a, 1, abc, ac, ab, b.

The response parameters are (1) disintegration time (2) the time for $80 \%$ (t $80 \%)$ of the drug to be released. The responses are given as mean values of three readings. The estimated effects of increasing the factors from a low to a high level were tested for significance by analysis of variance using Statistica computer program (University of Michigan-College of Pharmacy UM 10527937).

\section{Content of active ingredient}

The content of active ingredient was performed according to B.P 2005

Uniformity of diameter, thickness and hardness

10 tablets were taken from each batch and tested by using Erweka tester which measured the diameter, thickness and hardness.

\section{Friability}

10 tablets were weighed and placed in the friability tester (Erweka, Germany). The rotation rate was $25 \mathrm{rpm}$ for 4 minutes. The tablets were weighed again and loss was calculated by the following formula: Friability $=$

$$
\frac{\left(\mathrm{W}_{1}-\mathrm{W}_{2}\right) \times 100}{\mathrm{~W}_{1}}
$$

where $\mathrm{W}_{1}$ and $\mathrm{W}_{2}$ are the weight of tablets before and after rotation, respectively. 


\section{Uniformity of weight}

20 tablets were chosen randomly from each batch and weighed individually. The mean and standard deviation were calculated.

\section{Disintegration test}

The disintegration of tablets was performed according to B.P 2005 using disintegration tester (Erweka, Germany).

\section{Dissolution test}

The dissolution of paracetamol tablets was conducted on dissolution apparatus (Erweka, Germany) according to USP 2005 method.

\section{Results and Discussion}

Preparation of paracetamol tablets

Three excipients were chosen as formulation variables (PVP, stearic acid and Avicel PH101). PVP (factor A) was chosen as a binder. It was found that tablets containing soluble binders such as PVP had rapid dissolution rate $^{7}$. Stearates are the most effective lubricants. The level of stearic acid was set to $0.8-1.7 \% \mathrm{w} / \mathrm{w}$ of tablets. The low level of stearic acid was less than that mentioned in the literature because the Avicel PH101 has a lubricant effect ${ }^{8}$. Avicel PH101 (microcrystalline cellulose) is a very popular diluent. It has disintegrating properties; thereby this preparation doesn't contain a disintegrant.

Tablets were produced on flat punches since convex punched leads to capping. The moisture content is also important parameter.
To prevent sticking of the granules to punch faces the moisture content was set to $0.8 \%$.

\section{Characterization of paracetamol tablets}

All tablets have a uniform diameter, thickness and weight. The average paracetamol content of the tablets of the factorial design was $97 \%$ \pm 3 . The hardness of tablets of the factorial design is in the range of 107-196 N. The \% friability is less than $2 \%$.

\section{Experimental Design Disintegration time}

The disintegration time of paracetamol tablets was depicted in Table 3. The disintegration time was also chosen as a response parameter in the factorial design. The main effects of increasing the investigated factors from a low to a high level are shown in Table 4.

Table3. The disintegration time of tablets of the factorial design

\begin{tabular}{l|ll}
$\begin{array}{l}\text { Experiment } \\
\text { No. }\end{array}$ & $\begin{array}{l}\text { Replicate 1 } \\
\text { (sec.) }\end{array}$ & $\begin{array}{l}\text { Replicate II } \\
\text { (sec.) }\end{array}$ \\
\hline 1 & 29.7 & 29.0 \\
$\mathrm{a}$ & 88.0 & 100.3 \\
$\mathrm{~b}$ & 80.0 & 82.6 \\
$\mathrm{ab}$ & 35.0 & 29.3 \\
$\mathrm{c}$ & 64.3 & 79 \\
$\mathrm{ac}$ & 82 & 126.0 \\
$\mathrm{bc}$ & 25.0 & 35.3 \\
$\mathrm{abc}$ & 83.66 & 75.6
\end{tabular}

Table4. The results of analysis of variance for $2^{3}$ factorial experiment: The effect of three independent variables on the disintegration time.

\begin{tabular}{c|ccrrrc} 
Experiment No. & Main Effects & \multicolumn{1}{c}{ SS } & Df & \multicolumn{1}{c}{ MS } & \multicolumn{1}{c}{ F } & P \\
\hline $\mathrm{a}$ & 24.37 & 2375.59 & 1 & 2375.59 & 4.86 & 0.03 \\
$\mathrm{~b}$ & -18.98 & 1440.96 & 1 & 1440.96 & 2.33 & 0.16 \\
$\mathrm{c}$ & 12.12 & 587.59 & 1 & 587.59 & 0.95 & 0.35 \\
$\mathrm{ab}$ & -24.20 & 2343.53 & 1 & 2343.53 & 3.79 & 0.08 \\
$\mathrm{ac}$ & 16.54 & 1094.95 & 1 & 1094.95 & 1.77 & 0.22 \\
$\mathrm{bc}$ & -13.95 & 778.97 & 1 & 778.97 & 1.26 & 0.29
\end{tabular}

It is clear that the most important factor is factor A which is the binder $(\mathrm{P}<0.05)$. This is to be expected since binders have a cohesive strength that bind particles together and therefore, retard disintegration and increase the disintegration time. The disintegration of the tablets is not affected by Factor B (P> $0.05)$ although stearates retard disintegration ${ }^{9}$. This may be due to the presence of microcrystalline cellulose which have been 
shown to be highly porous with strong wicking tendencies and therefore, good disintegration properties ${ }^{10}$. It may counteract the action of the hydrophobic lubricant. There are no significant interactions between factors.

\section{Dissolution test:}

The percentage released of paracetamol from tablets replicate 1 and 2 of the factorial design was depicted in Figures 1 and 2, respectively.

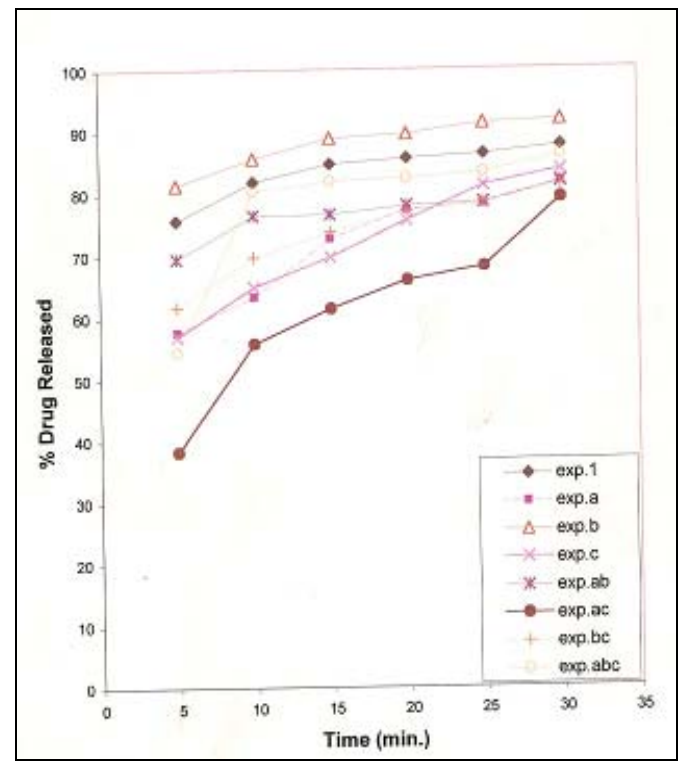

Figure1. Drug Released from Tablets of the Factorial Design Replicate 1

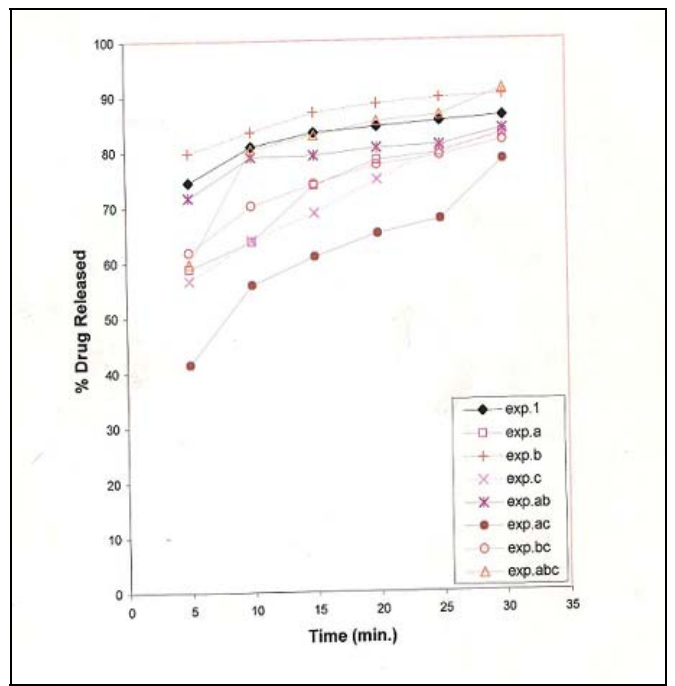

Figure1. Drug Released from Tablets of the Factorial Design Replicate 2.
The time for $80 \%$ ( $\mathrm{t} 80 \%$ of drug to be released was taken as a response parameter (Table 5).

Table5. The $\mathrm{t}_{80 \%}$ of the tablets of the factorial design

\begin{tabular}{c|cc}
$\begin{array}{c}\text { Experiment } \\
\text { No. }\end{array}$ & $\begin{array}{c}\text { Replicate 1 } \\
\text { (sec.) }\end{array}$ & $\begin{array}{c}\text { Replicate II } \\
\text { (sec.) }\end{array}$ \\
\hline 1 & 8.0 & 9.0 \\
$\mathrm{~A}$ & 27.5 & 25.5 \\
$\mathrm{~B}$ & 14.0 & 15.5 \\
$\mathrm{Ab}$ & 24.0 & 25.0 \\
$\mathrm{C}$ & 27.0 & 28.5 \\
$\mathrm{Ac}$ & 31.0 & 32.0 \\
$\mathrm{Bc}$ & 26.5 & 27.5 \\
$\mathrm{Abc}$ & 10.0 & 10.0
\end{tabular}

The obtained responses were listed in Table 6 . The experimental error is small as shown in table 6. All factors investigated in $2^{3}$ factorial design had a significant effect on $\mathrm{t} 80 \%$. The most important factor is Avicel PH 101 level $(\mathrm{P}<0.001)$. Avicel PH 101 is insoluble in water; therefore, it may decrease the wettability of paracetamol and thus decrease its release. Stearic acid (Factor B) is also important. Stearates are hydrophobic in nature. The granule surface is covered with a hydrophobic material which retards the dissolution of the granule. This is in accordance to the results of Levy et $\mathrm{al}^{11}$. who studied the release of salicylic acid from tablets contain different types of lubricants (3\% sodium lauryl sulphate, 3\% magnesium stearare, no lubricant). The slowest release of salicylic acid was found with tablets containing magnesium stearare. Povidone has a significant effect on dissolution of parcetaml tablets $(\mathrm{P}<0.01)$. PVP is characterized by its viscosity in aqueous solution and it is used as a viscosity increasing agent in a number of topical preparation, suspensions and solution ${ }^{12}$. As the concentration of PVP increases its viscosity increases and the diffusion of paracetamol through the viscous hydrodynamic layer of PVP slows. To illustrate that the dissolution of paracetamol is diffusion controlled, Higuchi plots were drawn as shown in Figure 3. 
Table6. The results of analysis of variance for $2^{3}$ factorial experiment: The effect of three independent variables on $\mathrm{t} 80 \%$.

\begin{tabular}{c|cccccl} 
Experiment No. & Main Effects & SS & Df & MS & F & \multicolumn{1}{c}{ P } \\
\hline $\mathrm{A}$ & 3.62 & 52.56 & 1 & 52.56 & 10.44 & 0.01 \\
$\mathrm{~B}$ & -4.50 & 81.00 & 1 & 81.00 & 16.08 & 0.003 \\
$\mathrm{C}$ & 5.50 & 121.00 & 1 & 121.00 & 24.03 & 0.0008 \\
$\mathrm{Ab}$ & -7.25 & 210.25 & 1 & 210.25 & 41.76 & 0.0001 \\
$\mathrm{Ac}$ & -10.25 & 420.25 & 1 & 420.25 & 83.47 & 0.0000080 \\
$\mathrm{Ab}$ & -6.63 & 175.56 & 1 & 175.56 & 34.87 & 0.000228 \\
Residual & & 45.31 & 9 & 5.03 & &
\end{tabular}

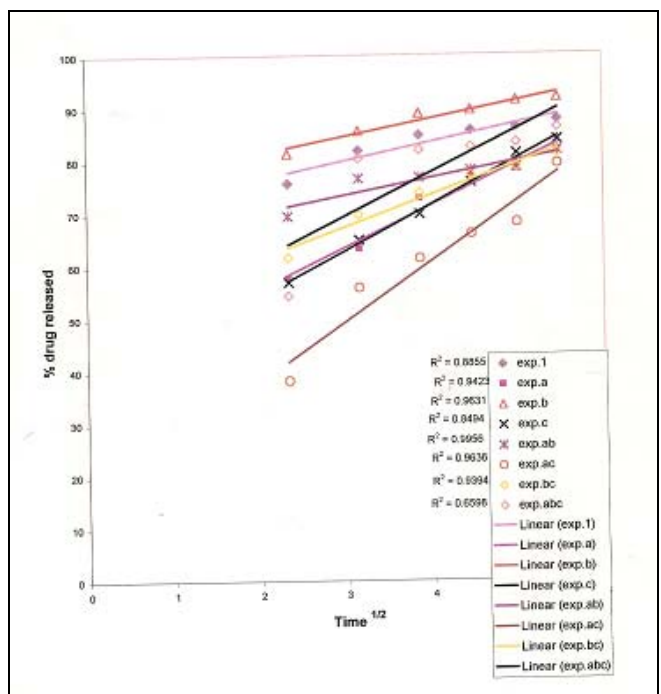

Figure 3. Higuchi Plot for the Tablets of the Factorial Design.

From this figure, $\mathrm{R}^{2}$ (regression coefficient) for most experiment is above 0.9. Therefore, the dissolusion of paracetamol is diffusion controlled.

\section{Conclusion}

The results suggest that factorial design could be useful to produce tablets with particular drug release profiles. Furthermore, there was considerable interaction between the variables as evidenced by the magnitude of the individual and interaction coefficient employed on the disintegration and dissolution times of paracetamol tablets. The concentration of binder A (Povidone), appears to be the most influential variable in disintegration time, In contrast, dissolution time is affected by all variables. This study would be useful in developing fast and long acting paracetamol tablets. In addition it could be applied to formulations for other drugs as well.

\section{Reference:}

1. Armstrong, N. Understanding experimental design and interpretation in pharmaceutics, Ellis Horwood, New York, 1990. pp. 27-54.

2. Box G., Hunter W., Hunter, J.. Statistics for experimenters, John Wiley and Sons, New York, 1978. pp. 306-351.

3. Montgomery, D. Design and analysis of experiments, $2^{\text {nd }}$ ed., John Wiley and Sons, New York, 1986. pp. 261-281.

4. Sanderson I, Kennerly J.W, Parrg D. An evaluation of the relative importance of formulation and process variables using factorial design. J. Pharm. Pharmacol. 2006; 36: 789-796.

5. Mohmud A., Wan A. Investigation of the effect of additives on dissolution rates of aspirin using a factorial design. Drug Dev.Ind.Pharm. 2007; 40: 709-714. 
6. Bakon N., Wade A. Martindale, the extra pharmacopeia, $26^{\text {th }}$ ed., The pharmaceutical press, London, 2004. pp. 564-573.

7. Mithal, M. Text book of pharmaceutical formulation, $2^{\text {nd }}$ ed., VallaH Parakashan, India, 2006. pp. 112-114.

8. Aulton M.E. Pharmaceutics: the science of dosage form design, Churchill livingstone, London, 2008. pp 304-321.

9. G. K. Bolhuis, A. J. Smallenbroek, C. F. Lerk, Interaction of tablet disintegrants and magnesium stearate during mixing I: Effect on tablet disintegration.
Journal of pharmaceutical sciences, J. Pharm. Sci. 1981; 70: 1328-1330.

10. Lachman Z., Herbert A., Joseph K., The theory and practice of industrial pharmacy, $3^{\text {rd }}$ ed., Varghess publishing house, Bombay, 2003. pp. 254-265.

11. Levy G., Gumlow R. Effect of certain tablet formulation factors on dissolution of active ingredient III: tablet lubricant. J. Pharm. Sci. 1993; 52: 1139-1141.

12. Ainley W., Weller P. Handbook of pharmaceutical excipient, $2^{\text {nd }}$ ed. The pharmaceutical press, London, 2008. pp. 294-297. 